\title{
Thin-plate spline analysis of mandibular shape changes induced by functional appliances in Class II malocclusion
}

\author{
A long-term evaluation
}

\section{TPS ("thin-plate spline")-Analyse morphologischer Unterkieferveränderungen durch funktionelle Apparaturen bei Klasse-II-Malokklusion}

\author{
Eine langfristige Evaluation
}

\author{
Lorenzo Franchi ${ }^{1,2}$ - Chiara Pavoni ${ }^{3,4}$ - Kurt Faltin ${ }^{5}$ Renato Bigliazzi ${ }^{5,6}$. \\ Francesca Gazzani ${ }^{3} \cdot$ Paola Cozza $^{3,4}$
}

Received: 7 November 2015/ Accepted: 5 February 2016/Published online: 29 June 2016

(c) Springer-Verlag Berlin Heidelberg 2016

\begin{abstract}
Aims The purpose of this work was to evaluate the longterm morphological mandibular changes induced by functional treatment of Class II malocclusion with mandibular retrusion.

Methods Forty patients (20 females, 20 males) with Class II malocclusion consecutively treated with either a Bionator or an Activator followed by fixed appliances were compared with a control group of 40 subjects (19 females, 21 males) with untreated Class II malocclusion. Lateral cephalograms were available at the start of treatment (T1, mean age 9.9 years), at the end of treatment with functional
\end{abstract}

Lorenzo Franchi

lorenzo.franchi@unifi.it

1 Department of Surgery and Translational Medicine, The University of Florence, Via del Ponte di Mezzo, 46-48, 50127 Florence, Italy

2 Department of Orthodontics and Pediatric Dentistry, School of Dentistry, University of Michigan, Ann Arbor, USA

3 Department of Clinical Sciences and Translational Medicine, University of Rome 'Tor Vergata', Rome, Italy

4 Department of Orthodontics, School of Dentistry, University Nostra Signora del Buon Consiglio, Tirana, Albania

5 Department of Orthodontics, School of Dentistry, University Paulista, São Paulo, Brazil

6 Department of Pediatric and Social Dentistry, Dental School of Araçatuba, São Paulo State University "Júlio de Mesquita Filho", Araçatuba, Brazil appliances (T2, mean age 12.2 years), and for long-term follow-up (T3, mean age 18.3 years). Mandibular shape changes were analyzed on lateral cephalograms of the subjects in both groups via thin-plate spline (TPS) analysis. Shape differences were statistically analyzed by conducting permutation tests on Goodall $\mathrm{F}$ statistics.

Results In the long term, both the treated and control groups exhibited significant longitudinal mandibular shape changes characterized by upward and forward dislocation of point Co associated with a vertical extension in the gonial region and backward dislocation of point B.

Conclusion Functional appliances induced mandible's significant posterior morphogenetic rotation over the short term. The treated and control groups demonstrated similar mandibular shape over the long term.

Keywords Class II malocclusion · Functional appliances · Thin-plate spline analysis $\cdot$ Cephalograms

\section{Zusammenfassung}

Aims Ziel dieser Arbeit war die Evaluation langfristiger morphologischer Unterkieferveränderungen durch die funktionelle Behandlung einer Klasse-II-Malokklusion mit mandibulärer Retrusion.

Methoden Insgesamt 40 Patienten (20 weiblich, 20 männlich) mit Klasse-II-Malokklusion wurden behandelt, zunächst mit einem Bionator bzw. Aktivater, anschließend mit festen Apparaturen. Zum Vergleich diente eine Kontrollgruppe mit 40 Individuen (19 w, $21 \mathrm{~m}) \mathrm{mit}$ 
unbehandelter Klasse-II-Malokklusion. Zu Beginn der Behandlung (T1, durchschnittliches Alter 9,9 Jahre) standen Fernröntgenseitaufnahmen zur Verfügung, ebenso bei Beendigung der Behandlung mit funktionellen Apparaturen (T2, durchschnittliches Alter 12,2) und für einen späten Follow-up-Termin (T3, durchschnittliches Alter 18,3). Die Veränderungen wurden auf den Fernröntgenseitaufnahmen der Individuen beider Gruppen mittels TPS ("thin-plate spline")-Analyse evaluiert. Morphologische Unterschiede wurden anhand von Permutationstests (Goodall-F-Statistiken) analysiert.

Ergebnisse Langfristig zeigten sich im longitudinalen Vergleich sowohl in der Behandlungsgruppe als auch in der Kontrollgruppe erhebliche Formveränderungen im Unterkiefer. Sie zeichneten sich aus durch eine Dislokation des Punktes Co nach oben und vorn in Verbindung mit einer vertikalen Verlagerung im Bereich des Gonium und einer Verschiebung des Punktes B nach posterior.

Schlussfolgerungen Funktionelle Apparaturen induzierten kurzfristig eine erhebliche posteriore morphogenetische Rotation. Langfristig zeigte sich allerdings in beiden Gruppen eine ähnliche Unterkieferform.

Schlüsselwörter Klasse-II-Malokklusion · Funktionelle Apparaturen · TPS ("thin-plate spline")-Analyse . Kephalogramme

\section{Introduction}

Class II malocclusion is one of the most common orthodontic problems, as it occurs in about a third of the population [14, 17, 24]. The most consistent diagnostic finding in Class II malocclusion is mandibular skeletal retrusion [19]. A series of treatment approaches aiming to stimulate mandibular growth by posturing the mandible forward are available to correct this type of skeletal and occlusal disharmony [7, 12, 21].

Due to the lack of long-term control groups made up of children with untreated Class II malocclusions, there is little definitive information on the long-term mandibular skeletal changes induced by functional treatment of Class II malocclusion [10, 16]. Recently, Franchi et al. [10] examined the long-term skeletal and dento-alveolar effects produced by functional appliances by enrolling untreated Class II subjects as controls. They found that significant improvements in the skeletal sagittal intermaxillary relationship were mainly due to the mandible's significant elongation versus the controls. However, the mechanisms that account for the long-term positive mandibular skeletal changes still need to be elucidated.

Thin-plate spline (TPS) analysis has become increasingly important in orthodontics as a means of investigating modifications in shape related to both facial growth and treatment $[9,26]$. Bookstein [6] proposed TPS analysis as a morphometric tool with which to compare configuration landmarks in two or more specimens. It is a descriptive method to follow shape and shape changes that was developed and implemented as a major improvement compared to conventional cephalometrics [20]. TPS analysis enables the construction of transformation grids that capture the differences in shape independently from size and are available for visual interpretation.

Lux et al. [15] used TPS analysis to evaluate dentofacial shape changes in Class II patients induced by early activator treatment. They found that in the activator group, the grid deformation of the total spline revealed a strong activator-induced reduction in the overjet caused by both the incisors' tipping and moderating sagittal discrepancies, particularly slight advancement of the mandible. Recently, the short- and long-term effects of the standard Balters' Bionator in growing patients with Class II malocclusion with mandibular retrusion were analyzed by means of TPS analysis [2, 4]. Both studies [2, 4] showed that the Bionator therapy with induced mandibular forward and downward displacement contributed significantly to correcting the Class II dentoskeletal imbalance. These results persisted upon long-term observation after completion of growth [4].

No data are available in the literature addressing the long-term mandibular shape changes produced by functional treatment of Class II malocclusion via geometric morphometric analysis. The aim of present study was to evaluate, by means of TPS analysis, the long-term mandibular morphological changes induced by functional treatment of Class II malocclusion.

\section{Subjects and methods}

\section{Subjects}

Our treated group consisted of 40 Class II division 1 patients (20 males, 20 females), who were consecutively treated with the Bionator (21 subjects: 10 females, 11 males) or Activator (19 subjects: 10 females, 9 males). The subjects were recruited from an orthodontic practice (Bionator) and from the records of patients treated in the Department of Orthodontics of the University of Rome Tor Vergata (Activator).

All patients in both the private practice and the university clinic were treated by two expert clinicians (P.C. and K.F.) whose clinical experience in managing the two functional appliances is very similar. All patients enrolled in the study were asked to wear the appliance $16 \mathrm{~h}$ per day until the end of treatment. As in studies involving any removable device, compliance with the instructions the 
Advertisement 
orthodontist and staff had given varied among the patients.

The Bionator and Activator produced a similar amount of mandibular advancement as the construction bites were registered in a similar way in both groups. The mechanism of action of these two monobloc appliances appears similar. As a matter of fact, Cozza et al. [7] evaluated the efficiency of functional appliances in stimulating mandibular supplementary elongation by dividing the supplementary elongation of the mandible obtained during the overall treatment period with the functional appliance by the number of months of active treatment (coefficient of efficiency). The Bionator and Activator yielded intermediate efficiency scores of 0.17 and $0.12 \mathrm{~mm}$ per month, respectively. For these reasons, we decided to combine patients treated with these two types of functional appliances.

This study project was approved by the Ethics Committee at the University of Rome Tor Vergata (178/14), and informed consent was obtained from the subjects' parents.

All patients had the following dentoskeletal features before therapy (T1) when the pretreatment lateral cephalogram was taken: overjet greater than $5 \mathrm{~mm}$, full Class II or end-to-end molar relationship, maxillomandibular differential smaller than $23 \mathrm{~mm}$ [18]. As for the skeletal maturation [3] at T1: 15 patients were at CS1, 10 at CS2, and 15 were at CS3. The stages of cervical vertebral maturation were determined by an operator (L.F.) calibrated in this method. No permanent teeth were congenitally missing or extracted before or during treatment. Demographics on the treated group (TG) are reported in Table 1.

The nonextraction treatment protocols consisted either of a Bionator constructed without coverage of the lower incisors [16] or of an acrylic monobloc attached to the upper arch by Adams clasps and capping the upper and lower incisors [8]. Therapy with functional appliances was considered complete once a Class I molar relationship had been achieved, followed by fixed appliance therapy in the permanent dentition.

All patients were re-evaluated at the end of functional jaw orthopedics (T2; 5 CS1, 5 CS2, 10 CS3, 18 CS4, 2 CS5) and at a follow-up observation at the end of growth
(T3; 1 CS4, 18 CS5, 21 CS6) by taking a set of lateral cephalograms (Table 1).

The success of therapy in terms of correcting the Class II malocclusion in each patient at the end of the observation period was not a determining factor for patient recruitment, an approach that lowered any potential selection bias.

A total of 40 subjects ( 21 males, 19 females) with untreated Class II division 1 malocclusion were selected from the American Association of Orthodontists Foundation Craniofacial Growth Legacy Collection (http://www. aaoflegacycollection.org, Bolton-Brush Growth Study, Michigan Growth Study, Denver Growth Study, Oregon Growth Study, and Iowa Growth Study) to comprise the control group (CG; Table 1). Skeletal maturation in the CG at T1 was 13 subjects at $\mathrm{CS} 1,9$ at $\mathrm{CS} 2$, and 18 at $\mathrm{CS} 3$; at T2 there were 4 subjects at CS1, 4 at CS2, and 12 at CS3, 16 subjects were at CS4, and 4 at CS5; at T3 we noted 2 subjects at CS4, 9 at CS5, and 29 subjects at CS6.

\section{TPS analysis}

Ten landmarks describing the mandibular region were identified and digitized (Fig. 1; Table 2) using appropriate software (Viewbox 3.1, dHAL Software, Kifissia, Greece) and a digitizing table (Numonics, Lansdale, PA, USA). Based on lateral films, cephalograms of all the subjects were hand-traced on a 0.03 -inch thick-frosted acetate paper by one investigator (C.P.) and checked by another (L.F.). In this study, TPS software (tpsRegr, version 1.38, Ecology and Evolution, SUNY, Stonybrook, NY, USA) computed the orthogonal least-squares Procrustes average configuration of mandibular landmarks in both TG and CG by using the generalized orthogonal least squares procedure described by Rohlf and Slice [25]. Procrustes average configurations were subjected to TPS analysis by cross-sectional comparisons of the $\mathrm{TG}$ with the $\mathrm{CG}$ at $\mathrm{T} 1$, at $\mathrm{T} 2$, and $\mathrm{T} 3$; longitudinal T1-T3 comparisons were also made between the two groups.

Shape differences were subjected to statistical analysis via permutation tests with 1000 random permutations on Goodall F statistics (tpsRegr, version 1.38, Ecology and Evolution, SUNY, Stonybrook, NY, USA).
Tab. 1 Demographics of the treated and control groups

Tab. 1 Demographische

Charakteristika der

Behandlungs- und der

Kontrollgruppe

\begin{tabular}{lccccc}
\hline Chronologic age (years) & \multicolumn{2}{c}{ Treated group $(N=40,20 \mathrm{f} 20 \mathrm{~m})$} & & \multicolumn{2}{c}{ Control group $(N=40,19 \mathrm{f} 21 \mathrm{~m})$} \\
\cline { 2 - 3 } & Mean & SD & & Mean & SD \\
\hline T1 & 9.9 & 1.7 & 10.3 & 1.1 \\
T2 & 12.2 & 1.8 & 12.3 & 1.1 \\
T3 & 18.3 & 2.6 & 18.1 & 1.0 \\
T1-T2 & 2.3 & 1.2 & & 2.0 & 0.3 \\
T2-T3 & 6.2 & 2.2 & & 5.8 & 1.0 \\
T1-T3 & 8.5 & 2.3 & 7.8 & 0.7 \\
\hline
\end{tabular}




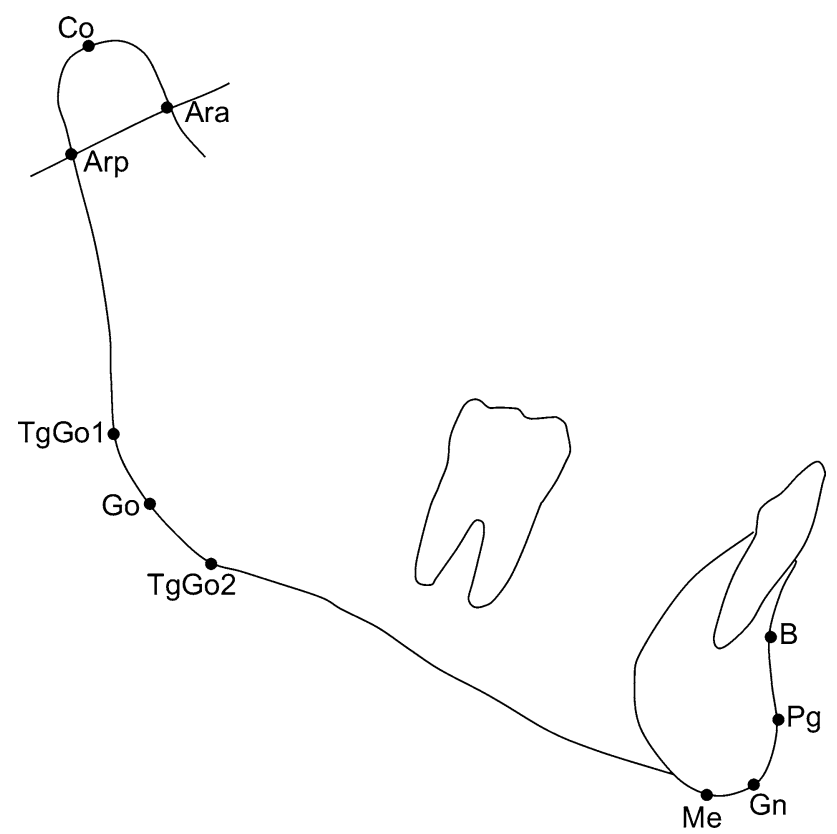

Fig. 1 Cephalometric mandibular anatomical landmarks (Table 2) Abb. 1 Anatomische kephalometrische Messpunkte an der Mandibula (Tab. 2)

Tab. 2 Definitions of landmarks used in this study

Tab. 2 Definitionen der in der Untersuchung verwendeten Messpunkte

\begin{tabular}{|c|c|}
\hline Abbreviation & Mandibular landmarks \\
\hline Ara & $\begin{array}{l}\text { Articulare anterior (intersection between the anterior } \\
\text { contour of the condyle and posterior cranial base) }\end{array}$ \\
\hline Co & $\begin{array}{l}\text { Condylion (most posterior-superior point on the } \\
\text { condyle) }\end{array}$ \\
\hline Arp & $\begin{array}{l}\text { Articulare posterior (intersection between the } \\
\text { posterior contour of the condyle and posterior } \\
\text { cranial base) }\end{array}$ \\
\hline TgGo1 & $\begin{array}{l}\text { Tangent gonion } 1 \text { (point of tangency on the line } \\
\text { passing through Arp to the gonial region) }\end{array}$ \\
\hline Go & Gonion (midpoint of the mandibular angle) \\
\hline $\operatorname{TgGo} 2$ & $\begin{array}{l}\text { Tangent gonion } 2 \text { (point of tangency on the line } \\
\text { passing through Me to the gonial region) }\end{array}$ \\
\hline $\mathrm{Me}$ & $\begin{array}{l}\text { Menton (the most inferior point on the symphyseal } \\
\text { outline) }\end{array}$ \\
\hline Gn & $\begin{array}{l}\text { Gnathion (the most anterior-inferior point on the } \\
\text { contour of the bony chin symphysis) }\end{array}$ \\
\hline $\mathrm{Pg}$ & $\begin{array}{l}\text { Pogonion (the most anterior point on the contour of } \\
\text { the bony chin) }\end{array}$ \\
\hline B & $\begin{array}{l}\text { B Point (the deepest point of concavity on the anterior } \\
\text { contour of the bony chin) }\end{array}$ \\
\hline
\end{tabular}

Group differences in chronologic age at T1, T2, and T3 and at the observation interval were tested with independent-samples $t$ tests while differences in gender distribution and in prevalence rates at the different stages of cervical vertebral maturation at $\mathrm{T} 1, \mathrm{~T} 2$, and $\mathrm{T} 3$ were subjected to $\chi^{2}$ tests (SPSS 12, SPSS Inc., Chicago, IL, USA).

To analyze the combined error of landmark location, tracing, and digitization method error, the same operator (L.F.) re-traced and re-digitized 20 randomly selected cephalograms to assess method error. Method of moments' estimator [27] was used to calculate the method error as a combination of the location of landmarks, tracing, and digitization for the $\mathrm{X}$ and $\mathrm{Y}$ co-ordinates of every cephalometric landmark.

\section{Results}

The method error ranged from a minimum of $0.20 \mathrm{~mm}(\mathrm{X}$ coordinate of point $\mathrm{Pg}$ ) to a maximum $1.11 \mathrm{~mm}(\mathrm{X}$ coordinate of point Go). No significant group differences were found either for chronologic age at T1, T2, and T3, for the observation intervals, for gender distribution, or for the prevalence rates at the different stages of cervical vertebral maturation at T1, T2, and T3. TPS analysis enabled us to analyze cross-sectional and longitudinal shape changes in the mandibular configurations in the TG and CG.

As for the cross-sectional comparisons, we observed no statistically significant mandibular shape changes between TG and CG at T1 $(P=0.064$; Table 3; Fig. 2). Crosssectional comparisons between the two groups at $\mathrm{T} 2$ revealed statistically significant mandibular shape changes $(P=0.002$; Table 3; Fig. 3). These shape differences can be attributed to an extended horizontal axis in the region of the mandibular condyle associated with backward dislocation of point Co. The horizontal extension in the symphysis region was due to forward dislocation of point $\mathrm{Gn}$. We detected no statistically significant mandibular shape

Tab. 3 Sum of residuals, Goodall F values and probability of statistical equivalence between mean mandibular configurations for the treatment group $(T G)$ and control group $(C G)$ groups as determined by Procrustes analysis and permutation tests (1000 random permutations)

Tab. 3 Summe der Residuen, Goodall-F-Werte und die Wahrscheinlichkeit für statistische Äquivalenz zwischen durchschnittlichen mandibulären Konfigurationen für die Behandlungsgruppe $(T G)$ und die Kontrollgruppe $(C G)$, bestimmt mittels Prokrustes-Analyse und Permutationstests $(n=1000$ zufällige Permutationen)

\begin{tabular}{llll}
\hline Group & Sum of residuals & $F$ value & $P$ value \\
\hline TG vs CG at T1 & 0.188389 & 2.318 & 0.064 \\
TG vs CG at T2 & 0.195329 & 4.600 & 0.002 \\
TG vs CG at T3 & 0.225379 & 1.920 & 0.105 \\
CG T1 vs CG T3 & 0.183143 & 6.613 & 0.001 \\
TG T1 vs TG T3 & 0.230501 & 5.175 & 0.003 \\
\hline
\end{tabular}




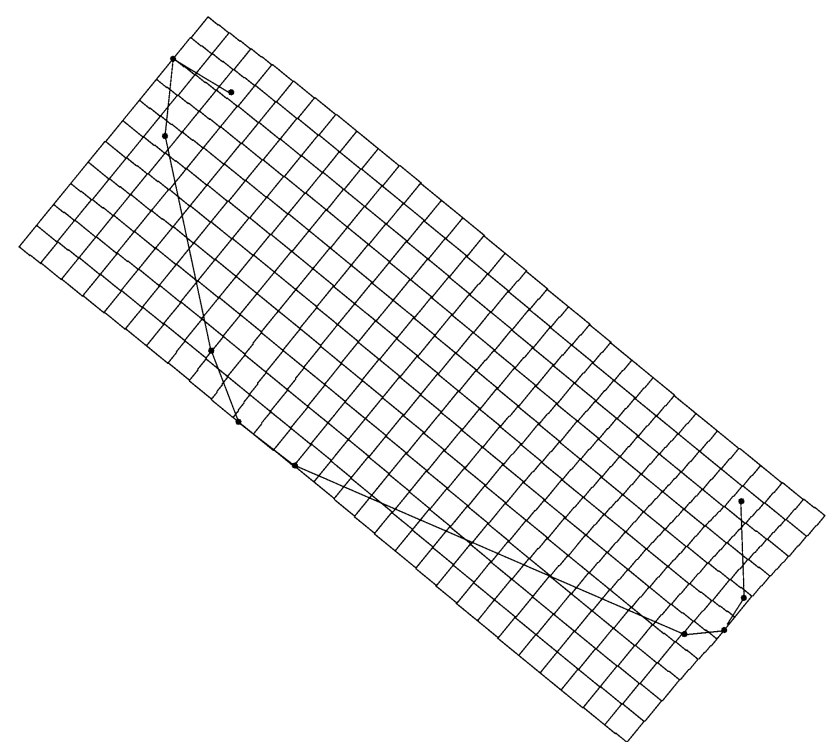

Fig. 2 Thin-plate spline (TPS) graphical display of cross-sectional mandibular shape changes between the control group and the treated group at T1 (magnification factor $\times 3$ )

Abb. 2 TPS ("thin-plate spline")-Analyse, graphische Darstellung der morphologischen Veränderungen in der Mandibula im Querschnitt, Kontroll- und Behandlungsgruppe zum Zeitpunkt T1. (Vergrößerung 3:1)

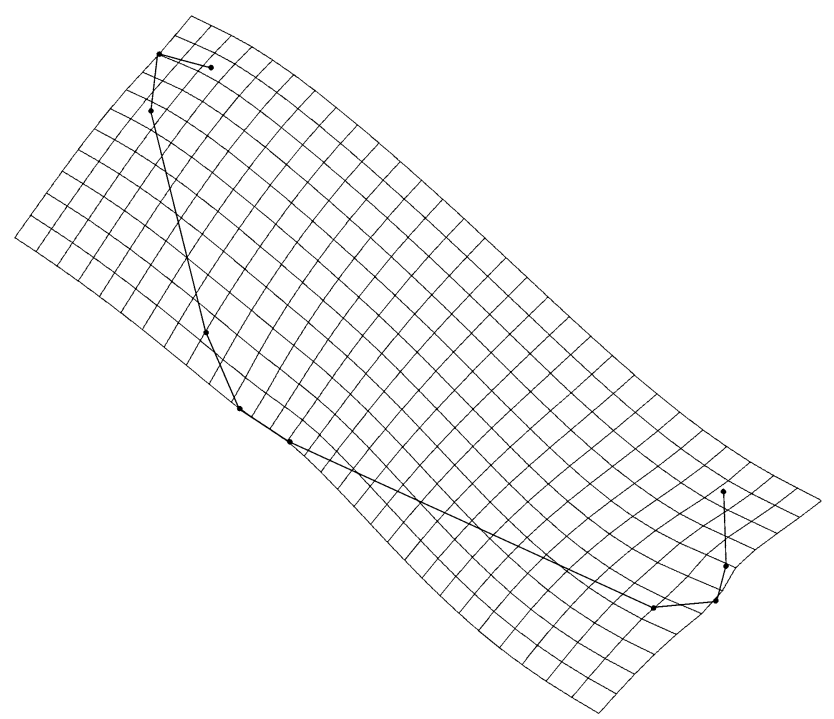

Fig. 3 Thin-plate spline (TPS) graphical display of cross-sectional mandibular shape changes between the control group and the treated group at T2 (magnification factor $\times 3$ )

Abb. 3 TPS ("thin-plate spline")-Analyse, graphische Darstellung der morphologischen Veränderungen in der Mandibula im Querschnitt, Kontroll- und Behandlungsgruppe zum Zeitpunkt T2. (Vergrößerung 3:1)

changes when comparing the $\mathrm{TG}$ and $\mathrm{CG}$ at $\mathrm{T} 3$ $(P=0.105$; Table 3; Fig. 4).

The longitudinal $\mathrm{T} 1-\mathrm{T} 3$ comparison in the TG revealed statistically significant $(P=0.003)$ mandibular shape

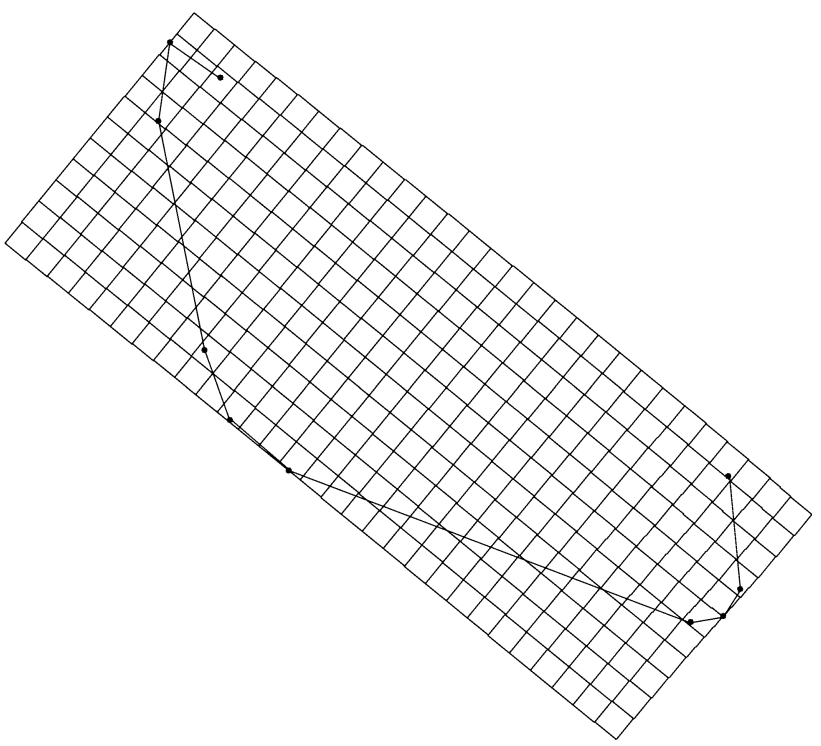

Fig. 4 Thin-plate spline (TPS) graphical display of cross-sectional mandibular shape changes between the control group and the treated group at T3 (magnification factor $\times 3$ )

Abb. 4 TPS ("thin-plate spline")-Analyse, graphische Darstellung der morphologischen Veränderungen in der Mandibula im Querschnitt, Kontroll- und Behandlungsgruppe zum Zeitpunkt T3. (Vergrößerung 3:1)

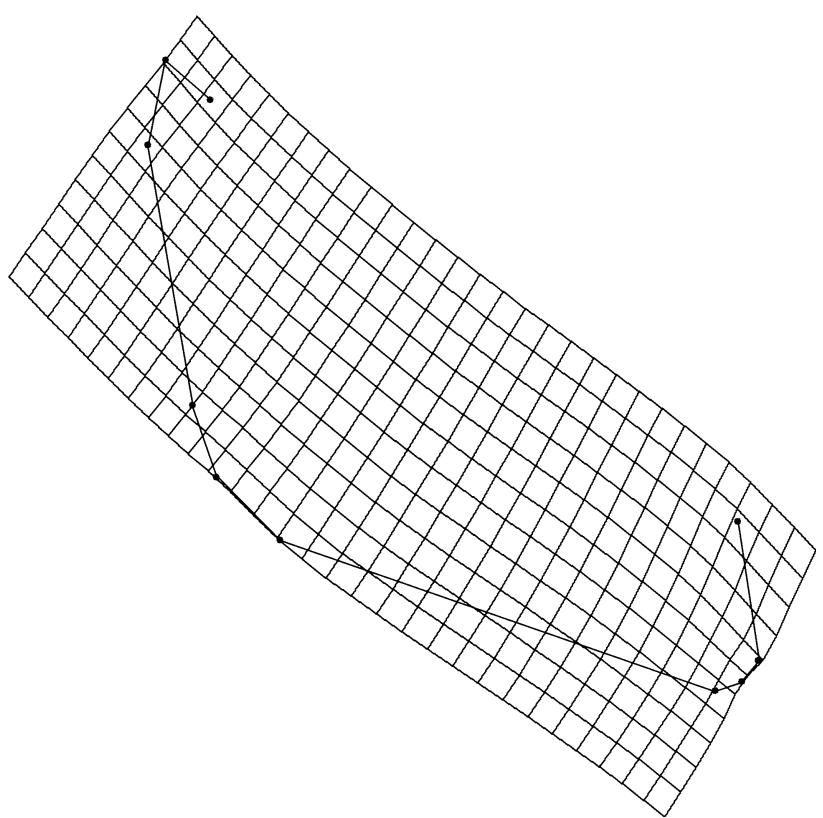

Fig. 5 Thin-plate spline (TPS) graphical display of longitudinal T1T3 mandibular shape changes in the treated group (magnification factor $\times 3$ )

Abb. 5 TPS ("thin-plate spline")-Analyse, graphische Darstellung der longitudinalen Unterkieferveränderungen in der Behandlungsgruppe im Zeitraum T1-T3. (Vergrößerung 3:1)

changes (Fig. 5). This deformation can be described as a vertical extension in the mandibular condyle's region associated mainly with the upward and forward dislocation 


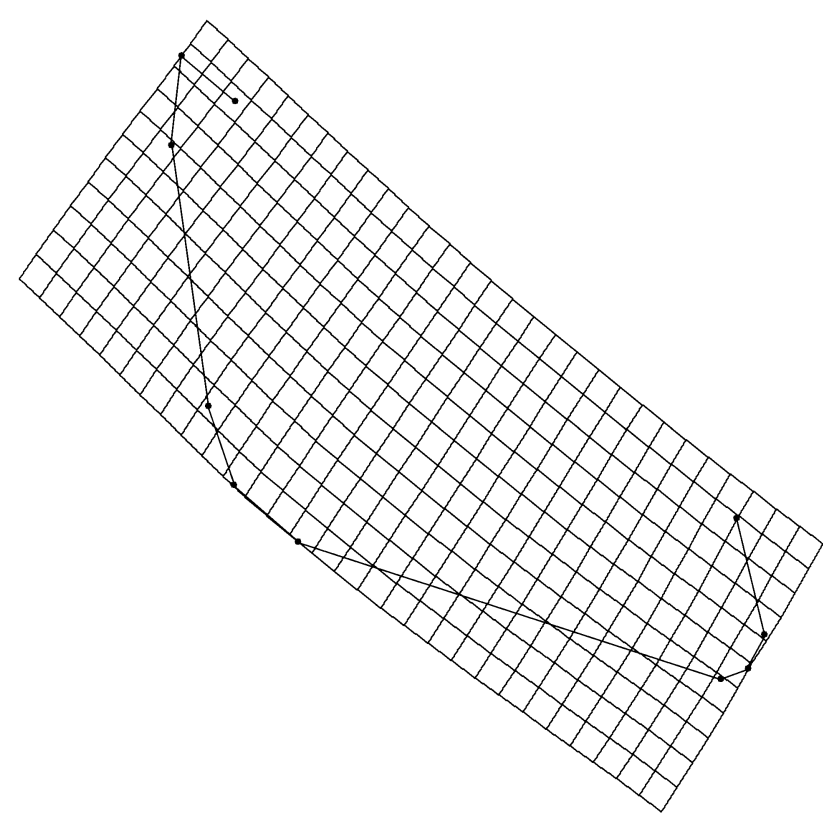

Fig. 6 Thin-plate spline (TPS) graphical display of longitudinal T1T3 mandibular shape changes in the control group (magnification factor $\times 3$ )

Abb. 6 TPS ("thin-plate spline")-Analyse, graphische Darstellung der longitudinalen Unterkieferveränderungen in der Kontrollgruppe im Zeitraum T1-T3. (Vergrößerungsfaktor 3:1)

of point Co. The vertical extension in the gonial region was due to downward dislocation of points Go and $\mathrm{TgGo}$. There was horizontal compression in the anterior region due mainly to the backward dislocation of point B.

Figure 6 illustrates the longitudinal T1-T3 mandibular shape changes in the CG. They displayed mandibular shape differences in the same direction as that in the TG regarding the longitudinal mandibular shape changes.

\section{Discussion}

The aim of present study was to evaluate, by means of TPS analysis, the long-term mandibular shape and size changes induced by functional treatment in growing Class II patients in comparison with a historical sample of untreated Class II controls. Although historical control groups may be a limitation [22], we used historical controls in this study for ethical reasons, as it would have been impossible to recruit a contemporary control group of subjects with untreated Class II malocclusion for long-term observation.

The major advantages of TPS analysis of cephalometric landmark configurations over both conventional cephalometrics and previous morphometric techniques (tensor analysis, shape-coordinate analysis) include

- optimal superimposition of landmarks for analyzing shape change in complex skeletal configurations without having to refer to any conventional reference lines,
- explanatory visualization of the deformations caused by growth/treatment using transformation grids, and

- the delineation of generalized modifications into more specific, local changes [6].

A more appropriate procedure would have been to use sliding semilandmarks that enable homologous curves via sets of points, establishing geometric homology between corresponding semilandmarks across the sample [11].

Skeletal effects of functional therapy of Class II malocclusions in growing subjects remain a controversial topic in orthodontics. A recent long-term controlled study [10] on the effects of functional appliances showed no short- or long-term effects in the maxilla, although favorable modifications were documented in the mandible that consisted of significant mandibular elongation that was maintained over the long term. Similarly, in their long-term morphometric investigation Bigliazzi et al. [4] demonstrated that Bionator treatment for Class II malocclusion triggered significant craniofacial shape changes characterized by mandibular forward and downward displacement. In the present investigation we aimed to assess mandibular shape changes produced by functional appliances via morphometric analysis. A limitation in this study is the relatively small size of our TG and $\mathrm{CG}$ that rendered gender-specific analysis infeasible. We did not determine sample sizes in advance, as it is difficult to arrive at the appropriate sample size when relying on geometric morphometrics. A consequence of the relatively limited sample size in a study using multivariate methods is related to interpreting the $P$ values. For example, the $P$ value of 0.064 in Table 3 is very close to statistical significance. A slightly larger study cohort may have revealed a statistically significant difference between CG and TG at T1.

TPS analysis showed significant differences in mandibular shape in the cross-sectional comparison between the TG and CG at T2 and in the longitudinal T1$\mathrm{T} 3$ comparisons between both groups also.

The significant difference in mandibular shape at $\mathrm{T} 2$ can be described as a horizontally extended grid along the entire mandibular length (Co-Gn). This shape difference can be interpreted as a "posterior mandibular morphogenetic rotation" a biological mechanism that contributes to the sagittal skeletal correction of Class II disharmony, as it is associated with "stretching" along the entire mandible. No significant difference in mandibular shape between groups was noted at T3. Interestingly, Petrovic [23] reported similar findings after applying an hyperpropulsor to rats, noting that after administering the hyperpropulsor, the mandibular shape changed, revealing an opening of Stutzmann's angle (that between the mandibular plane and orientation of the newly formed endochondral bone in the condyle). Stutzmann's angle opening must be considered a 
transient phenomenon, as normal mandibular shape is observed at the end of growth [23]. Johnston [13] also reported that functional appliances are capable of achieving molar and overjet corrections without exerting any longterm impact on the pattern of mandibular growth. It should be stressed, however, that Franchi et al. [10] observed that functional appliances induce significant long-term elongation of the mandible, unlike in untreated Class II controls $(+3.6 \mathrm{~mm})$.

One of the most interesting findings in this study was that the longitudinal shape changes in both study groups were essentially similar. TPS analysis showed that the significant mandibular shape changes that occurred between $\mathrm{T} 1$ and $\mathrm{T} 3$ in both groups involved mainly the mandibular condyle, which exhibited an upward-forward direction of growth-a sign revealing anterior growth rotation of the mandible [5]. Those findings concur with Franchi et al. [10], who found that both treated patients and control subjects exhibited closure of the mandibular angle (Co-Go-Me) that was associated with a reduction in the inclination of the mandibular plane to the Frankfort horizontal.

In the longitudinal T1-T3 group comparison we noted a backward dislocation of point $\mathrm{B}$, which has been associated with the lower incisors' proclination [1]. Previous controlled, long-term cephalometric studies [10, 16], however, failed to identify significant long-term Bionator-induced proclination of the lower incisors.

We observed that the vertical component of condylar growth was also associated with an elongated mandibular ramus. In particular, the T1-T3 longitudinal comparisons within the treated group revealed a downward dislocation of point Gonion, findings that are in line with previous controlled long-term cephalometric studies [10, 16] that reported a significant long-term increase in the height of the mandibular ramus as a result of Bionator therapy.

The present study also helped us elucidate some interesting aspects of mandibular growth in subjects with untreated Class II malocclusion over the long term. Untreated Class II subjects exhibited mandibular shape changes in the same direction (anterior rotation) as did the treated patients. We noted that an upward direction of condylar growth was associated with point B's backward dislocation, with no deformation of the mandibular symphysis.

\section{Conclusion}

- Treatment with functional appliances induced a significant posterior morphogenetic rotation of the mandible over the short term. This significant shape difference was not maintained over the long term, when the treated and control groups revealed similar mandibular shape.

- The longitudinal T1-T3 mandibular shape changes were similar in the treated and control subjects. The mandible displayed anterior rotation, with the condyle presenting an upward and forward growth direction associated with a vertically elongated mandibular ramus and backward dislocation of point $\mathrm{B}$.

\section{Compliance with ethical guidelines}

Conflict of interest L. Franchi, C. Pavoni, K.Faltin, R. Bigliazzi, F. Gazzani, and P. Cozza state that there are no conflicts of interest. All studies on humans described in the present manuscript were carried out with the approval of the responsible ethics committee and in accordance with national law and the Helsinki Declaration of 1975 (in its current, revised form). Informed consent was obtained from all patients included in studies.

\section{References}

1. Al-Abdwani R, Moles DR, Noar JH (2009) Change of incisor inclination effects on points A and B. Angle Orthod 79:462-467

2. Antunes CF, Bigliazzi R, Bertoz FA et al (2013) Morphometric analysis of treatment effects of the Balters bionator in growing Class II patients. Angle Orthod 83:455-459

3. Baccetti T, Franchi L, McNamara JA Jr (2005) The cervical vertebral maturation (CVM) method for the assessment of optimal treatment timing in dentofacial orthopedics. Sem Orthod 11:119-129

4. Bigliazzi R, Franchi L, de Magalhaes Bertoz AP et al (2015) Morphometic analysis of long-term dentoskeletal effects induced by treatment with Balters bionator. Angle Orthod 85:790-798

5. Björk A (1969) Prediction of mandibular growth rotation. Am J Orthod 55:585-599

6. Bookstein FL (1991) Morphometric tools for landmark data. Cambridge University Press, New York

7. Cozza P, Baccetti T, Franchi L et al (2006) Mandibular changes produced by functional appliances in Class II malocclusion: a systematic review. Am J Orthod Dentofacial Orthop 129:599.e1-12

8. Cozza P, De Toffol L, Iacopini L (2004) An analysis of the corrective contribution in activator treatment. Angle Orthod 74:741-748

9. Franchi L, Baccetti T, Stahl F et al (2007) Thin-plate spline analysis of craniofacial growth in Class I and Class II subjects. Angle Orthod 77:595-601

10. Franchi L, Pavoni C, Faltin K Jr et al (2013) Long-term skeletal and dental effects and treatment timing for functional appliances in Class II malocclusion. Angle Orthod 83:334-340

11. Bookstein FL (1997) Landmark methods for forms without landmarks: morphometrics of group differences in outline shape. Med Image Anal 1:225-243

12. Heinrichs DA, Martin C, Razmus T et al (2014) Treatment effects of a fixed intermaxillary device to correct class II malocclusions in growing patients. Prog Orthod 15:45

13. Johnston LE Jr (1996) Functional appliances: a mortgage on mandibular position. Aust Orthod J 14:154-157

14. Kelly JE, Harvey C (1977) An assessment of the teeth of youths 12-17 years. DHEW Publication No (HRA) 77-1644. National Center for Health Statistics, Washington, DC 
15. Lux CJ, Rubel J, Starke J et al (2001) Effects of early activator treatment in patients with Class II malocclusion evaluated by thin-plate spline analysis. Angle Orthod 71:120-126

16. Malta LA, Baccetti T, Franchi L et al (2010) Long-term dentoskeletal effects and facial profile changes induced by bionator therapy. Angle Orthod 80:10-17

17. McLain JB, Proffit WR (1985) Oral health status in the United States: prevalence of malocclusion. J Dent Educ 49:386-396

18. McNamara JA Jr, Brudon WL (2001) Orthodontics and dentofacial orthopedics. Needham Press, Ann Arbor

19. McNamara JA Jr (1981) Components of a Class II malocclusion in children 8-10 years of age. Angle Orthod 51:177-202

20. Moyers RE, Bookstein FL (1979) The inappropriateness of conventional cephalometrics. Am J Orthod 75:599-617

21. Neves LS, Janson G, Cançado RH et al (2014) Treatment effects of the Jasper Jumper and the Bionator associated with fixed appliances. Prog Orthod 15:54

22. Pandis N (2012) Use of controls in clinical trials. Am J Orthod Dentofac Orthop 141:250-251
23. Petrovic A (1985) Research findings in craniofacial growth and the modus operandi of functional appliances. In: Graber TM, Rakosi T, Petrovic A (eds) Dentofacial orthopedics with functional appliances. Mosby, St. Louis, Missouri, USA, pp 36-38

24. Proffit WR, Fields HW, Moray LJ (1998) Prevalence of malocclusion and orthodontic treatment need in the United States: estimates from the N-HANES III survey. Int J Adult Orthod Orthognath Surg 13:97-106

25. Rohlf FJ, Slice DE (1990) Extensions of the procrustes method for the optimal superimposition of landmarks. Syst Zool 39:40-59

26. Singh GD, McNamara JA Jr, Lozanoff S (1997) Thin-plate spline analysis of the cranial base in subjects with Class III malocclusion. Eur J Orthod 19:341-353

27. Springate SD (2012) The effect of sample size and bias on the reliability of estimates of error: a comparative study of Dahlberg's formula. Eur J Orthod 34:158-163 